\title{
Lung cancer masquerading as fungus-associated mucoid impaction
}

\author{
Kohei Horiuchi, ${ }^{1}$ Takanori Asakura, ${ }^{1,2}$ Shinji Sakaguchi, ${ }^{1}$ Fumitake Saito ${ }^{1}$
}

'Department of Pulmonary Medicine, Eiju General Hospital, Taito-ku, Tokyo, Japan ${ }^{2}$ Division of Pulmonary Medicine, Department of Medicine, Keio University School of Medicine, Shinjuku-ku, Tokyo, Japan

\section{Correspondence to} Dr Kohei Horiuchi, kohei.horiuchi17@gmail.com

Accepted 7 December 2018

\section{DESCRIPTION}

A 64-year-old healthy man with mild haemoptysis for a month was referred to our hospital. He had no other symptoms, and physical examination was unremarkable. He had a 40-pack-year smoking history. Chest CT showed mucoid impaction-like consolidation from the bronchus to the lingular segment but no lymphadenopathy (figure 1A). Bronchoscopy was not performed as he refused further investigations owing to improvement in haemoptysis, and he was lost to follow-up. Eight months later, he was readmitted to our hospital due to deterioration of chest radiograph findings. Chest CT revealed a large mass in the lingular segment (figure 1B). Laboratory examination revealed a total leucocyte count of $6.3 \times 10^{9} / \mathrm{L}$ (range: $\left.3.5-8.5 \times 10^{9} / \mathrm{L}\right)$ with a total eosinophil percentage of 2.6\% (range: $1 \%-6 \%$ ), total serum IgE levels of 1370 $\mathrm{IU} / \mathrm{mL}$ (range: $<173 \mathrm{IU} / \mathrm{mL}$ ), and Aspergillus fumigatus-specific IgE of $<0.10 \mathrm{kUA} / \mathrm{L}$ (range: $<0.35 \mathrm{kUA} / \mathrm{L}$ ). Serum tumour markers, including carcinoembryonic antigen, cytokeratin 19 fragments and pro-gastrin-releasing peptide, were within normal levels and were similar to the levels 8 months before admission. Bronchoscopy revealed a tumour obstructing the lingular bronchus with a thick mucus plug (figure 2A). Pathological examination of the mucus plug revealed fungal filaments (figure 2B). Transbronchial biopsy specimen of the tumour showed squamous cell carcinoma (SCC)
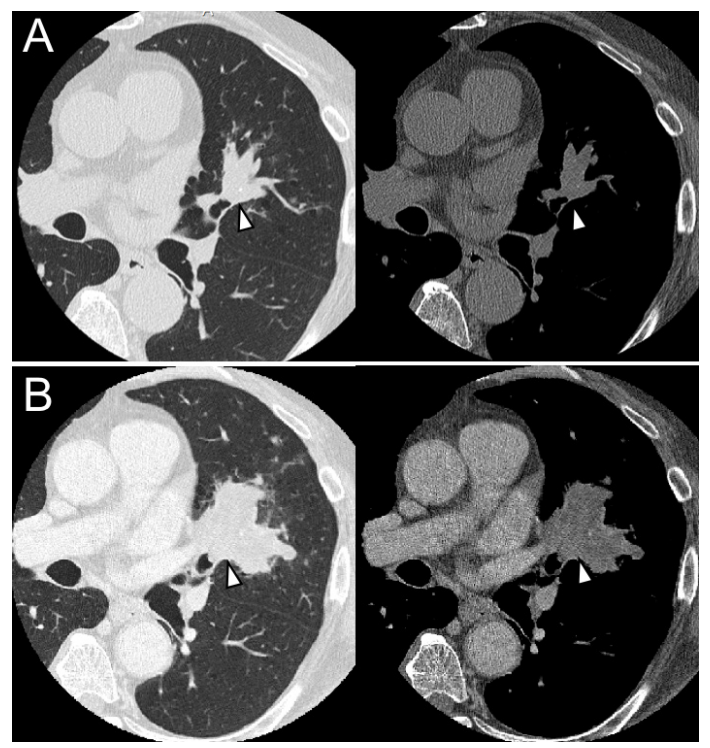

Figure 1 Chest CT at the referral showed mucoid impaction-like consolidation (arrow) in the distal bronchus of the lingular segment $(A) ; 8$ months later, a mass was noted in the lingular segment (arrow) (B). Horiuchi K et al.

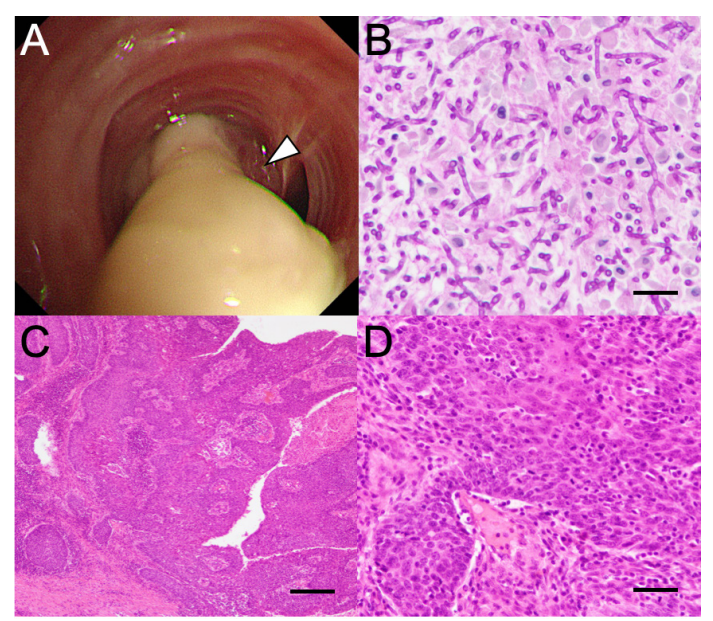

Figure 2 Bronchoscopy revealed a tumour (arrow) obstructing the lingular bronchus with thick mucus plug in the lingular segment (A). Periodic acid-Schiff staining of the mucus plug revealed a distinct dichotomous acute angle branching of the septate hyphae with orientation of branches in similar direction (B) (scale bar $=25 \mu \mathrm{m}$ ). Surgical specimen of the tumour stained with $\mathrm{H} \& \mathrm{E}$ showed the presence of squamous cell carcinoma (C,D) (scale bar $=200 \mu \mathrm{m}(C),=50 \mu \mathrm{m}(\mathrm{D}))$. Horiuchi $\mathrm{K}$ et al.

of the lung. He underwent left upper lobe lobectomy to treat obstructive pneumonia which developed after SCC diagnosis. Analysis of surgical specimens revealed SCC (figure 2C, D) without any lymphatic or vessel involvements; there were no evidence of eosinophilic inflammation and fungal infection. The patient was followed up without any complication 1 month after the surgery.

This case revealed evidence of mucoid impaction associated with fungal infection in a patient with lung SCC. Mucoid impaction, a clinical radiographic syndrome manifested by inspissated mucus plugs of the bronchi, most commonly occurs in patients with inflammatory conditions such as allergic bronchopulmonary aspergillosis (ABPA)/mycosis (ABPM); however, as in this case, it is also observed in patients with benign and malignant conditions causing airway obstruction. ${ }^{1}$ Although the morphology of the filamentous fungus was similar to that of Aspergillus, we were unable to confirm the species, as the culture result from the bronchial wash was not positive for any fungus. Further molecular tests were not available at our clinical site. When tests were performed using sputum-derived cultures obtained from 213 Japanese patients with ABPA/ ABPM, Aspergillus species and Schizophyllum commune were identified in 126 (59\%) and 12 
(6\%) patients, respectively. ${ }^{2}$ Although the morphological differentiation between S. commune and Aspergillus ${ }^{3}$ was found to be difficult in previous cases, both species could be identified as filamentous fungus in our case.

A previous study conducted in patients with bronchogenic carcinoma, most commonly those with SCC, showed a high prevalence of Aspergillus colonisation in the bronchoalveolar lavage. ${ }^{4}$ Additionally, another study revealed that subacute invasive aspergillosis can occur in patients with primary lung cancer owing to the anatomical changes and systemic factors compromising the immune response..$^{5}$

\section{Learning points}

- Physicians should rule out lung cancer in patients presenting with mucoid impaction.

- Lung cancer, especially bronchogenic squamous cell carcinoma, can cause fungal colonisation with mucoid impaction.
Contributors $\mathrm{KH}, \mathrm{SS}$ and FS provided patient care and designed the study. $\mathrm{KH}$ and TA wrote the initial draft of the manuscript. FS supervised the study and suggested critical revisions regarding important intellectual content. All authors approved the final version as submitted to the journal.

Funding The authors have not declared a specific grant for this research from any funding agency in the public, commercial or not-for-profit sectors.

Competing interests None declared.

Patient consent Obtained.

Provenance and peer review Not commissioned; externally peer reviewed.

\section{REFERENCES}

1 Shah RJ, Kotloff RM. Beware of gloved fingers. Ann Am Thorac Soc 2013;10:56-8.

2 Oguma T, Taniguchi M, Shimoda T, et al. Allergic bronchopulmonary aspergillosis in Japan: A nationwide survey. Allergol Int 2018;67:79-84.

3 Ishiguro T, Takayanagi N, Tokunaga D, et al. Pulmonary Schizophyllum commune infection developing mucoid impaction of the bronchi. Yale J Biol Med 2007;80:105-11.

4 Ali S, Malik A, Bhargava $R$, et al. Aspergillus colonization in patients with bronchogenic carcinoma. Asian Cardiovasc Thorac Ann 2014;22:460-4.

5 Peghin M, Ruiz-Camps I, Garcia-Vidal C, et al. Unusual forms of subacute invasive pulmonary aspergillosis in patients with solid tumors. J Infect 2014;69:387-95.

Copyright 2018 BMJ Publishing Group. All rights reserved. For permission to reuse any of this content visit https://www.bmj.com/company/products-services/rights-and-licensing/permissions/

BMJ Case Report Fellows may re-use this article for personal use and teaching without any further permission.

Become a Fellow of BMJ Case Reports today and you can:

Submit as many cases as you like

- Enjoy fast sympathetic peer review and rapid publication of accepted articles

- Access all the published articles

- Re-use any of the published material for personal use and teaching without further permission

For information on Institutional Fellowships contact consortiasales@bmjgroup.com

Visit casereports.bmj.com for more articles like this and to become a Fellow 